\title{
¿Cómo reescribir la historia de la historiografía? Prolegómenos para una historia de la verdad en la historia*
}

\author{
How to Rewrite the History of Historiography? Prolegomena for a \\ History of the Truth in History
}

\author{
Guillermo Zermeño Padilla \\ gmoz@colmex.mx \\ Profesor/Investigador \\ El Colegio de México, A. C., Centro de Estudios Históricos \\ Camino al Ajusco No. 20, Col. Pedregal de Sta. Teresa \\ 10740 - México - DF \\ México
}

\begin{abstract}
Resumen
¿Cómo se podría reescribir la historia de la historiografía a principios de este siglo? Este artículo es un intento de responder a esa pregunta poniendo en juego las relaciones entre cuatro vocablos: la historia, la ciencia, la verdad y la credibilidad. La revisión y transformación que se han hecho de las categorías, conceptos o formas de representación de la historia producida durante la modernidad nacionalista nos llevan a cuestionar la manera en que es posible escribir la historia actualmente, ya que esas viejas formas que se establecieron en lugares comunes historiográficos producidos en el siglo XIX y XX parecen haberse agotado. En ese sentido, se pretende mostrar cómo la crisis de una epistemología histórica de carácter "naturalista" dio lugar a la posibilidad de considerar la disciplina de la historia como parte de un fenómeno más amplio: el de la cultura y su relación con la forma en que las sociedades recuerdan u olvidan. Al mismo tiempo, ese desplazamiento ha implicado también la construcción de otra clase de memoria social: la apertura a la comprensión de la historia como una especie de memoria cultural.
\end{abstract}

\section{Palabras clave}

Historia; Verdad; Discurso.

\begin{abstract}
How could rewrite the history of historiography in this century? This paper tries to answer this question using just four words: history, science, truth and credibility. The revision and transformation that has been done over the categories, concepts or ways of representing history, created during the nationalist modernity, leads us to question is it how possible to write history nowadays since when those old contents and forms that settled historiographical commonplaces produced in the $19^{\text {th }}$ and $20^{\text {th }}$ centuries seem to have become exhausted. Therefore, we try to show how the crisis of a historical epistemology of "naturalistic" character gave rise to the possibility of considering historical discipline as part of a larger phenomenon: that of culture and its relationship to how societies remember or forget. At the same time, this displacement has also implied in the construction of another class of social memory: the opening to the understanding of history as a kind of cultural memory.
\end{abstract}

Keywords

History; Truth; Discourse.

Recibido el: 6/12/2013

Aprobado el: 18/7/2014

\footnotetext{
* Este ensayo es la versión corregida de la Conferencia de apertura del $6^{\circ}$ Seminário Brasileiro de História da Historiografia (SNHH), "O Giro Linguístico e a Historiografia: balanco e perspectivas", realizado em Mariana, Minas Gerais, Brasil, de 20 a 23 de agosto de 2012. Expreso mi gratitud especial por aquellos espléndidos días en Mariana a Valdei Lopes de Araujo y Marcelo de Mello Rangel; y a Rogério Forastieri da Silva por su excelente História da Historiografia. Registro, también, mi reconocimiento a los dictaminadores anónimos por su lectura y sus certeras observaciones y sugerencias.
} 
Al aproximarnos a algunos trabajos históricos recientes queda la impresión de que la historiografía contemporánea se ha convertido en un inmenso baúl de curiosidades, de relatos e investigaciones dedicados a sorprender y asombrarnos con todas aquellas cosas que ignoramos del pasado o simplemente ni imaginábamos que hubieran podido suceder, muchos de ellos sin duda de gran interés. No obstante, cabría preguntarse acerca de los límites de esa proliferación de historias que nos llegan día a día y seguirán llegando a través de diferentes medios y soportes comunicativos. Esa acumulación de relatos históricos puede recordarnos aquella fascinación surgida en el periodo premoderno de la historia anticuaria o el gusto por la recolección de objetos y materiales exóticos y excéntricos. ${ }^{1}$ Eso sucede, desde luego, no sólo en nuestras lenguas. Son textos y relatos sin duda fascinantes por la novedad y el enfoque crítico que, en muchos casos, nos obligan a modificar y revisar nuestras concepciones del pasado o de las formas en las que se ha querido entender un periodo o un fenómeno determinado y que responden sin duda también a las nuevas sensibilidades y atmósferas culturales de nuestros presentes.

Al mismo tiempo, puede verse que muchas de esas "nuevas" historias, sobre todo aquellas dedicadas al periodo premoderno, coinciden en la crítica a muchos de los discursos históricos surgidos y fabricados durante el periodo de las modernidades nacionalistas. ${ }^{2}$ En ese sentido, en forma análoga al diagnóstico crítico del "discurso filosófico de la modernidad" del sociólogo alemán Jurgen Habermas (1989), se podría vislumbrar una galería significativa de historiadores

348 que se han dado a la tarea de revisar y cuestionar, mediante análisis rigurosos, muchos de los lugares comunes historiográficos asentados durante el lapso comprendido entre los siglos XIX y XX. Esos discursos e historias se ofrecen como la verdad sin más del pasado, al mismo tiempo en que ocultan sobre todo el modo en que esas "verdades" fueron producidas. Y gran parte de su fuerza y vigencia se encuentra en el artificio de mostrar y ocultar a la vez un pedazo de la verdad en la que se sostienen las aseveraciones y representaciones del pasado. Por ejemplo, en una investigación reciente sobre la historia del concepto de archivo se ha encontrado en algunos tratados del siglo XVIII cómo se aconsejaba al anticuario erudito que se guardara para él mismo una parte del secreto, que no mostrara completamente la "verdad" para, así, poder mantener el efecto de sorpresa, suspenso y atracción en sus lectores y consumidores de esa clase de relatos (ZERMEÑO PADILLA 2012, p. 13-57).

Se trataría, entonces, de relatos de cosas añejas, críticos del discurso histórico elaborado durante la modernidad, o aquel periodo constituyente de la formación de los estados nacionales a partir de 1800 hasta nuestro presente. Y en el ejercicio de esa función crítica del discurso historiográfico de la modernidad es indudable la importancia que han tenido historiógrafos como Hayden White (Metahistory: the historical imagination in Nineteenth-Century Europe, 1973),

\footnotetext{
1 "Anticuarios" ocupados en atraer la atención del presente hacia las "antigüedades", lo "extraño", lo "exótico", las cosas "curiosas" (KRIEGEL 1988, p. 221-264; POMIAN 2003, p. 177-191). En esa afición por la "ruinas" del pasado no deja de mostrarse, entre otras cosas, una cierta melancolía (BREDEKAMP 1996).

2 Para un ejemplo significativo relacionado con el ejercicio del poder, véase MAZIN 2012.
} 
Frank Ankersmit (La experiencia histórica sublime, 2010 [2007]), François Hartog (Evidence de I'histoire: ce que voient les historiens, 2005) y Hans Ulrich Gumbrecht (Dimensionen und Grenzen der Begriffsgeschichte, 2006), por mencionar sólo algunos. ${ }^{3}$ Tampoco se deben olvidar las contribuciones tempranas de principios de 1970 de Michel de Certeau (L'ecriture de l'histoire, 1975) y de Michel Foucault ( L'archéologie du savoir, 1969) en su afán de revelarnos la mecánica oculta o no reconocida en la producción de todo discurso sobre el pasado.

A partir de lo anterior se podría pensar que la historia como disciplina académica está inmersa en un periodo de revisión y transformación de muchas de las categorías de análisis, formas de narrar y periodizar que han dado sustento y estructurado sus formas discursivas construidas principalmente a partir del siglo XIX. Para muchos, es verdad, ese "revisionismo" no significaría más que la destrucción de la historia o el fin de la historia como se ha venido conociendo y practicando.

Lo anterior nos ha llevado a pensar ${ }^{4}$ que probablemente en la actualidad la producción historiográfica podría dividirse en dos grandes campos: el de los productores de monografías, cuyo volumen tiende a crecer exponencialmente, ${ }^{5}$ y aquel otro terreno que se preocupa menos por la escasez o abundancia de la información y se concentra principalmente en esclarecer el modo en que se producen y han producido los acontecimientos históricos. Es en ese segundo nivel en donde se situarían mis reflexiones y comentarios acerca de cómo podría reescribirse una historia de la historiografía moderna, cuestión que me ha ocupado desde hace algunos años. Mi intención se concentra, entonces, solamente en presentar el esbozo incipiente de una respuesta posible a dicha interrogación en la cual se pondrán en juego fundamentalmente las relaciones entre historia, ciencia, verdad y credibilidad.

\section{De la filosofía a la sociología de la ciencia}

Como bien sabemos, la justificación de la historia como ciencia siguió de cerca durante largo tiempo el paso marcado por la filosofía de la ciencia. Fue necesario que durante la segunda mitad del siglo XX la sociología desplazara a la filosofía para que la historia pudiera establecer relaciones más justas con la ciencia con vistas a su legitimación disciplinaria. La sociología del conocimiento desarrollada hacia mediados del siglo pasado ha permitido redescribir una noción de verdad inmutable, absoluta, no relativa, al mostrar cómo los factores culturales son también determinantes en la aceptación de las verdades, sean de orden natural o cultural (SAHLINS 2011). Por otra parte, sabemos que la historia sigue manteniendo una relación ambigua con los progresos de las llamadas ciencias exactas, sin percatarse de que la ciencia experimental moderna estuvo

\footnotetext{
3 Por ejemplo, al despuntar el nuevo siglo, un reconocido historiador medievalista nos deja ver sus preferencias (RUIZ-DOMENEC 2000).

${ }_{4}$ En concordancia con otros acercamientos desde otras disciplinas, como la historia del cine o del arte (QUINTANA 2011; DIDI-HUBERMAN 2008; BELTING 2010; DANTO 1999).

${ }^{5}$ Eso confirmaría el pronóstico de Jorge Luis Borges para el siglo XXI según el cual la gran pesadilla del historiador radicaría en la dificultad creciente para escribir debido al exceso de materiales y de información (QUINTANA 2011, p. 188).
} 
también sujeta a factores y procedimientos no necesariamente asépticos. Tal reconocimiento conduciría al establecimiento de otra clase de relaciones entre historia y ciencia (hasta ahora caracterizadas por la subordinación de una hacia la otra) y a la posibilidad de un diálogo más equitativo y provechoso entre ambas.

Para abordar el tema me remito a algunos trabajos de la llamada escuela de Edimburgo, en particular a las contribuciones de uno de sus integrantes, Steve Shapin (1994, p. 3-41), quien se propuso hacer una historia social de la verdad para mostrar su relatividad frente a filósofos académicos que sotendrían lo contrario. La verdad sería concebida por este autor solamente como uno de los mecanismos de selección que una sociedad, un grupo, un individuo, realiza para operar en su vida práctica. Si bien no es lo mismo saber algo que detentar una "verdad", lo que importaría aquí es poder distinguir por medio de qué mecanismos un saber ordinario se constituye en "la verdad".

En ese contexto, para ese colectivo transdisciplinario, "el tratamiento de la verdad como una creencia aceptada" se constituiría en el principio heurístico metodológico rector. A partir del hecho de que la verdad puede ser pronunciada desde distintas voces y registros, se trataría de saber cómo cada uno de sus participantes considera algo como verdadero o como falso. Este punto de partida los lleva, entonces, a poner entre paréntesis - a la manera de un recurso hermenéutico- su noción de verdad para abrirse a la posibilidad de entender lo que otros tienen por cierto. Al final, de lo que se trataría es de poder entender cómo se da la variación cultural en relación con la verdad (POOVEY 1998;

3.50 SHAPIN; SCHAFFER 1985; SHAPIN 2000). En ese sentido, su cometido es poder mostrar que es posible una aproximación sociohistórica a la verdad, rigurosa y valiosa, para comprender la complejidad propia de la producción de toda clase de verdades. Desde luego, lo hacen en discusión y frente a quienes (la filosofía, un tipo de historia, etcétera) adoptan una posición normativista y juridicista ( $a$ priorística), postulando que es posible todavía establecer la verdad de una vez por todas como si se tratara de una sustancia atemporal.

\section{Verdad, medios de comunicación e historia}

Precisamente en mi acercamiento al problema planteado, recurro también a la obra de un querido colega y amigo, Alfonso Mendiola, especialista en los siglos XVI y XVII. En su trabajo Retórica, comunicación y realidad: la construcción retórica de las batallas en las crónicas de la conquista (2003), Mendiola ha adelantado algunas de las cuestiones relacionadas con el problema de cómo historizar la verdad en la historia. Se trata de una aproximación que, en principio, trata de ver el modo en que se puede desustancializar o pluralizar la noción de verdad.

Uno de los aspectos centrales de su libro es el abordaje de cómo en la modernidad científica se conformó la tópica (lugares comunes) que desplazó y sustituyó paulatinamente a las formas tradicionales imbricadas en el arte de la retórica renacentista. Del análisis se desprende a grandes rasgos que la tópica moderna se bifurcó en dos direcciones: de un lado, habría verdades como resultado de la explicación a partir de leyes (modelo nomológico-deductivo) y, 
del otro, se tendrían verdades como resultado de la explicación comprensiva de naturaleza polivalente y contextualista. El primer polo pertenecería a la ciencia de la naturaleza y el segundo, a la historia entendida como una ciencia de la cultura. Visto así, la modernidad científica oscilaría entre dos direcciones opuestas: entre la razón científica experimental, por un lado, y la razón hermenéutica, débil o relativa, por el otro.

Para despejar satisfactoriamente esa contraposición clásica se postularía como solución la hipótesis siguiente. En la producción de verdad o sentido de realidad cuentan más las tecnologías de comunicación que las estructuras psíquicas subjetivas. Así, lo que se denominaría "ciencia" sería el resultado progresivo de un cambio tecnológico en los medios de comunicación y no, como solía pensare, el resultado de alguna mente genial. Siguiendo ese razonamiento, se podría añadir que, entonces, quien logra entender el funcionamiento de los medios de comunicación dispondría de mejores elementos para entender la producción de versiones diferentes de realidad o de verdad. ${ }^{6}$

Si consideramos ese binomio (producción de conocimiento/evolución de los medios de comunicación), es posible mostrar que el modelo dualista absoluto/ relativo, explicativo/comprensivo, exacto/hermenéutico, se correspondería con el impacto creciente que tuvo la invención de la imprenta en la cultura caligráfica. Una de las contribuciones más originales de la indagación de Mendiola a partir del análisis de las crónicas de la Conquista consiste en mostrar la relación existente entre algunos de los principios que regulan la producción científica moderna y la instalación de la cultura del escrito como una forma dominante de comunicación en el establecimiento de los acuerdos sociales. En un ensayo posterior, Mendiola profundizará en una distinción fundamental para entender dicha instalación y sus repercusiones en la forma de consensuar lo falso y lo verdadero: la que existe entre las formas orales y escritas de comunicación. Mientras en el primer caso la producción de lo real emerge de la distinción entre el habla (el sonido) y la cosa en simultaneidad con el momento en que ocurre, el paso de la escritura como anotación a la escritura como comunicación implicó la posibilidad de separar la representación de la cosa de la cosa referida (LUHMANN 2002, p. 3-21; MENDIOLA 2002, p. 11-38). De esa manera, en vez de desaparecer la escritura para internarse en la realidad, las escrituras (gracias a su difusión por la imprenta) se convertirán en condición de posibilidad y garante de toda verdad $y$, al mismo tiempo, en el instrumento regulador de la relación entre lo real y lo irreal. El acto de escribir y su difusión se convirtieron paulatinamente en el referente de lo referido, indicando con ello la posibilidad de distinguir entre lo escrito y la realidad observada, natural o cultural (DE CERTEAU 1975). Bajo el mandato de observar con los propios ojos sin intermediarios, las escrituras funcionarían como el espejo en el que se ha de reflejar la realidad; un espejo en constante perfeccionamiento en función de los errores atisbados o de nuevos hallazgos. En ese sentido, especialmente a partir del siglo XVII, la cultura del 
impreso se transformó en el referente de la realidad y condición de posibilidad de toda verdad futura.

Un segundo aspecto cabe destacar relacionado con la transformación operada principalmente en el siglo XX y que ha venido a problematizar las formas clásicas de producción de la verdad: el desarrollo y ampliación de la comunicación a distancia por vía de la electrónica. Su impacto se puede observar en la revisión a que ha sido sometida la noción de verdad establecida por la alianza entre mundo y escritura. ${ }^{7}$ La sociología del conocimiento y la filosofía analítica del lenguaje son también algunas expresiones del intento de descosificar la noción de verdad fabricada durante la modernidad temprana. Estas "sociologías" y "filosofías" críticas sin duda no son pensables sin el establecimiento de un nuevo escenario en las formas y los medios masivos de comunicación. A partir de esas consideraciones puede explicarse que el siglo XX haya tomado distancia de un modelo de ciencia conformado durante la expansión de la cultura del escrito durante la segunda mitad del siglo XVIII, sin la cual no es explicable el movimiento intelectual alrededor de la Encyclopedie y la Ilustración. El "atrévete a pensar por ti mismo" de Kant no es pensable sin la explosión del mundo de los libros entre hombres y mujeres de la segunda mitad del siglo XVIII y la voluntad de distanciamiento de la llamada "edad oscura", incluida la impronta del Renacimiento (KANT et al. 1980).

Asimismo, a partir de los trabajos de Thomas Kuhn (aunque no exclusivamente), se observa cómo la historia de la ciencia vendría a ocupar el 3.52 lugar ocupado anteriormente por la filosofía de la ciencia (BETANCOURT 2007). Una de las implicaciones de ese desplazamiento consistió en el reconocimiento de que la verdad de los hechos observados no depende exclusivamente de su descripción exacta, sino, sobre todo, de la forma en que se inscriben dentro de una determinada narración. Esa aseveración conlleva el hecho de que la aceptación de la verdad de la verdad está en relación directa con el mismo proceso en el que se produce. De ahí se seguiría: 1) que para la comprensión de la historia de la verdad haya que observar la formación y funcionamiento de las comunidades científicas; y 2) que la pregunta teórica clásica sobre la naturaleza científica de la explicación histórica se traslade al problema de la investigación acerca de la función de la explicación en la configuración narrativa del discurso histórico.

Trasladar la localización de la verdad de una producción meramente individual a una social y comunitaria abre la cuestión acerca de la importancia que tienen las formas de comunicación para que eso suceda o no suceda. Eso implicaría asumir el teorema postulado por Luhmann de que la sociedad está conformada no por la suma de acciones individuales, sino por comunicaciones (LUHMANN 1996). De lo anterior se seguiría que la verdad es un bien relativo a la evolución de las tecnologías de comunicación (MENDIOLA 2002).

Sin embargo, ese postulado requiere de una precisión ulterior relacionada con el fenómeno de la comunicación y del lenguaje en general. Al respecto, es fundamental la distinción elaborada por Luhmann entre lenguaje entendido como

$\overline{7}$ No otro es el contexto en el que habría que situar el libro ya "clásico" de Lyotard (1990). 
medio y como forma de comunicación. El lenguaje es análogo a otros medios cuyos márgenes son inobservables, pero sin los cuales no es posible delimitar y vislumbrar las cosas y los objetos. Así, por medio de la luz se distinguen los objetos, o por medio del aire se distinguen los sonidos, o por medio del lenguaje se distinguen formas (géneros) diferenciadas de comunicación. ${ }^{8}$ En esas operaciones entran en juego básicamente el sentido del oído y el de la vista en una relación inestable, a veces en una relación de complementariedad o, aún, de oposición abierta. En la lectura silenciosa que se desarrolla en Occidente se tenderá a dar prioridad a la visión (externa e interior) en detrimento del oído. Esa contraposición entre el oído y el ojo cobrará importancia, por ejemplo, cuando se discuta acerca de si Herodoto era más confiable como historiador que Tucídides. Más tarde, con la creciente colonización llevada a cabo por la escritura en detrimento de la información circulante de oído en oído (convertida en rumor, sospechosa y peligrosa), surgirán, al interior del sistema o forma del escrito, los géneros "literarios", en los que se incluye la diferenciación creciente entre el relato de ficción y el relato verídico o histórico (COSTA LIMA 1988). En ese sentido se puede sostener que el lenguaje no es una forma, sino un medio de comunicación a través del cual las sociedades adquieren y crean formas específicas (LUHMANN 1996, p. 130-139; MENDIOLA 2003, p. 79-82).

Arribamos así al punto nodal de nuestra argumentación. De acuerdo con la teoría de la sociedad luhmanniana, no habría comunicación mientras no exista el contacto entre un alter y un ego, entre un emisor y un receptor. ${ }^{9}$ Pero, al mismo tiempo, se parte del supuesto de que la comunicación es uno de los hechos más improbables en los que se ven inmersos los seres humanos. No obstante - y esa sería la paradoja central sobre la cual se articula la argumentación-, sólo a partir de esa improbabilidad es que surgen y se desarrollan los sistemas sociales, o las formas en que los humanos están programados para convertir la improbabilidad en probabilidad. En ese sentido, se trataría de una paradoja productiva (LUHMANN 1996, p. 238-240).

Si no hay sociedad sin comunicación, entonces, alrededor de una probable historia de la historiografía la cuestión central consistiría en saber cómo de la improbabilidad se producen identificaciones y reconocimientos entre hablantes y oyentes, entre escritores y lectores. La respuesta al enigma estaría en que, a partir del déficit comunicativo inicial, las sociedades y las comunidades de pensamiento generan mecanismos suplementarios para hacer posible el triunfo de los síes sobre los nóes entre los oyentes. En relación con nuestra investigación la pregunta sería la siguiente: ¿qué clases de mecanismos hubieron de generarse para reforzar la aceptación y desarrollo de un tipo de comunicaciones históricas y científicas? En este punto es donde coinciden en lo fundamental la sociología luhmanniana y la sociología histórica representada por Steven Shapin.

Un ejemplo de ello nos lo proporciona Mendiola a partir de su estudio sobre la producción y circulación de las crónicas de la Conquista en el siglo XVII

\footnotetext{
8 Por ejemplo, para el campo literario, ver GENETTE et al. 1986.

9 Por ejemplo, habría que explicar como algún hombre de estado en algún lugar consigue obtener el $100 \%$ de los síes en un referéndum; un $100 \%$ que implicaría un contacto comunicativo pleno entre el político y el "pueblo".
} 
(MENDIOLA 2003). Ahí se deja ver cómo en una sociedad gobernada por una cultura oral secundaria -en la que las formas orales de comunicación coexisten con las formas de la escritura caligráfica- se adaptaron los manuales de retórica clásicos para reforzar y asegurar los intercambios comunicativos establecidos preponderantemente en los linderos de la oralidad. Así, el recurso del arte de la retórica antigua permitió dar una cierta profundidad temporal a relaciones sociales marcadas por el presentismo y asegurar nuevos enlaces comunicativos. Pero, ante todo, la retórica cumplió durante ese periodo la función de reforzar la posibilidad de obtener la aceptación o el reconocimiento entre un alter y un ego. Además, el uso de la retórica - apoyada en el desarrollo incipiente de la imprenta- coincidió con los primeros brotes de la revuelta "metódica" en contra de la misma retórica. Era un momento en el que se iba imponiendo el mandato de la observación de la naturaleza con los propios ojos como reacción a la creciente multiplicación y circulación de los libros impresos. Así, el problema que se avecina y que compete a la estructuración del campo científico está relacionado con la clase de mecanismos que una sociedad crecientemente alfabetizada tuvo que desarrollar para resolver el problema de la comunicación a distancia implicado en la producción creciente de impresos. ¿Qué clase de mecanismos se implantaron en el proceso de sustitución de la retórica para asegurar la aceptación de los enunciados empíricos no alegóricos? La respuesta se encontraría en la aparición y desarrollo de los "medios simbólicamente generalizados", noción central en la teoría de la sociedad de Luhmann y a la cual me referiré en el siguiente inciso.

3.54 A partir de los factores mencionados se podría afirmar que la ciencia moderna emergió simultáneamente gracias a y en contra de la retórica; eso es, la ciencia fue posible en la medida en que la retórica decaía y perdía credibilidad debido en buena parte a la creciente autonomización de la escritura con respecto a la palabra hablada. En ese sentido, no es de extrañar - como lo dejan ver estudios de historia cultural sobre ese tema y periodo- que las sociedades científicas y literarias que proliferaron a partir del siglo XVII anticipen retrospectivamente la formación de una opinión pública moderna (GOUBERT; ROCHE 1991, p. 219-254). En ese marco, la cuestión es acerca de la clase de recursos que tuvieron que desarrollarse para reforzar y convencer al público a partir de formas de comunicación mediadas por la distancia espacial temporal y la interposición del impreso.

Una respuesta posible se puede desdoblar en cinco aspectos: 1) una medida suplementaria para cubrir el déficit propio de toda comunicación tendría que ver, como lo asienta Steven Shapin, con el desarrollo de una nueva clase de "civilidad" o formas de cortesía; 2) se desarrolla, además, un nuevo tipo de sintaxis gramatical, una escritura recursiva y abierta a la novedad; 3) surgió también un nuevo sentido de temporalidad que amplía el horizonte de expectativas (el futuro) en relación con las constricciones del presente; 4) apareció un nuevo sentido de objetividad construido a partir de la distinción entre representación y realidad; y 5) habría un desplazamiento de la retórica por la ciencia experimental que implicó la construcción de otro tipo de memoria social o de formas de recordar. 
Tal vez ese quinto aspecto sea el más relevante debido a sus implicaciones con respecto a la revisión que estamos haciendo en relación con la noción de verdad en la historia, ya que significa la apertura a la comprensión de la historiografía como un tipo de memoria cultural (BIZIERE; VAYSSIERE 1995, p. 232; DOSSE 2000, p. 169-193). Mendiola nos recuerda que la retórica era, ante todo, "una técnica de memorización". En una sociedad oral de "pocos libros" y bibliotecas incipientes o muy localizadas, sobre la base del arte de la retórica se desarrolló un tipo de memoria espacial e interior. El lugar de la memoria es interno y se accede a ella por medio de la imaginación para evocar lo ya conocido como digno de recordar. ${ }^{10}$ En cambio, bajo el régimen científico, la biblioteca es el lugar objetivante de la memoria; es exterior al que recuerda o aprende algo nuevo. El saber almacenado y a la vista de todos es confrontado con el trabajo de campo, con los viajes y las observaciones en el terreno, moda que tenderá a cobrar una gran relevancia a partir del siglo XVIII. El laboratorio se convierte en el enlace final que pone en juego la realidad libresca y la empírica, que confronta los lenguajes naturales con los especializados. Si en la sociedad retórica la memoria se sirve de las autoridades o de los sabios o clásicos para recrear los saberes y domesticar el azar, la cuestión es ver cómo la modernidad científica en su rebelión contra ese esquema de producción de saber (por medio de imágenes externas e internas) generó sus propias autoridades para reforzar y hacer extensivos sus dominios (MENDIOLA 2003, p. 160-197).

\section{Verdad, historia y credibilidad}

Hemos heredado una noción de verdad que aspira a establecer una correspondencia plena o aproximada entre la representación y lo representado, la escritura y el mundo. Sin embargo, dejada atrás su "ingenuidad", esa noción se ha topado con la imposibilidad de fijar o encontrar la palabra exacta y definitiva para nombrar las cosas en la medida en que la forma "verdad" es relativa al medio utilizado para su observación y enunciación. De ahí se deriva en parte la necesidad de disponer de un concepto de verdad que sea histórico, un concepto de verdad contingente que no es lo mismo que verdad relativa o subjetiva. Se requiere, además, deshacer un concepto de subjetividad ajustado al modelo de ciencia implicado en la distinción sujeto/objeto y en una teoría de la acción intencional centrada en la conciencia de individuos aislados. ${ }^{11}$

La reprogramación de la noción de verdad desde esa perspectiva no implica caer en el abismo del relativismo y la arbitrariedad, como se quiere hacer creer, porque el concepto no se deriva de la mente de un individuo, sino de la sociedad. La verdad en ese sentido no es patrimonio exclusivo de los individuos aislados, ni tampoco el resultado de la suma estadística de todos los individuos, sino, más bien, es el resultado de la evolución de las formas de comunicación a lo largo de la historia, de modo tal que cada una de esas "formas" se correspondería con un tipo de producción de verdad, a saber: 1)

\footnotetext{
${ }_{10}$ Un buen ejemplo del desarrollo y funcionamiento de esta clase de memoria se puede ver en SPENCE 2002

11 Tal es el cometido de Habermas al intentar trazar "la prehistoria del positivismo moderno" (HABERMAS 1968, p. 9).
} 
alegórica, que toma la forma de la metáfora o juego de símiles; 2) empírica o positiva, que toma la forma de descripciones-explicaciones; y 3) cibernética, que toma la forma de imagen virtual. Esas tres clases se corresponderían con la formación de tres tipos de memorias sin las cuales no hay posibilidad de comunicación: 1) memoria corporal introspectiva, 2) memoria centrada en el sujeto y 3) memoria virtual descentrada. Indicar que las clases de verdad no son relativas a la acción del individuo sino a las formas de comunicación en las que se inscribe la acción supone la emergencia de tres clases de subjetividad relativas a tres clases de comunicación: 1) oral, 2) escrita y 3) telemática. En cada una de ellas se presentan a su vez subgéneros o formas de coexistencia e hibridación que cumplen las funciones específicas en cada una de las formas de comunicación. Asimismo, cada una de las formas genera formas de temporalidad y socialización diferenciadas, familiares, educativas, legales y políticas.

La clave de esa taxonomía sociológica radicaría en la distinción entre lenguaje como medio de comunicación y lenguaje como forma de comunicación. El lenguaje, como se dijo, es un medio y sólo es estructurable a partir de sus formas, que remiten a los objetos indicados. En ese esquema, uno de los principales retos para la investigación histórica y sociológica consistiría en poder identificar y maniobrar con posibles superposiciones o subconfiguraciones que podrían darse en el tránsito de una forma de comunicación a otras, tanto en relación con la transformación de la forma como en las coexistencias con otras formas. En ese sentido, uno de los hallazgos de la investigación de Mendiola 3.56 tiene que ver con el uso que hace de la noción de "oralidad secundaria" para explicar la coexistencia de la oralidad (como medio dominante de socialización en la era premoderna) y la escritura, que condujo al uso de la retórica para reforzar los acuerdos entre presentes; es decir, para hacer posible el paso de la improbabilidad comunicativa a una probabilidad entre otras. Es verdad que el desarrollo de la retórica se presentó también como un medio para producir y conservar el saber necesario para el funcionamiento de una sociedad regida por las interacciones entre presentes y que daría lugar, como se dijo antes, a la constitución de otras formas de producción y conservación de los saberes, propias de nuestra modernidad científica.

En ese marco, se podría trazar una periodización provisional con los siguientes resultados. Se tendría que, durante la emergencia del pensamiento científico, entre 1550 y 1650, aproximadamente, se realizó el primer gran debate sobre el método para controlar y ordenar el saber que se produce ya no por medio de la retórica (que requiere de un número determinado de autores y sabios), sino por medio de la observación de la naturaleza que se ha ido sedimentando en los libros. La operación ya no es la de un individuo que sabe porque recuerda, sino la de un observador que verifica si lo sabido es verdadero o falso al confrontar lo sabido con las nuevas informaciones ofrecidas por el entorno. De esa manera, la escritura ( $y$ no la memoria introspectiva) se fue convirtiendo paulatinamente en el referente de la realidad y de la verdad referida.

A continuación se podría esbozar un segundo periodo que va de finales del siglo XVII hasta el siglo XIX y en el que se dio el desarrollo y codificación de 
una segunda manera de observar y producir conocimiento. Durante ese lapso se desarrolló al lado de la ciencia natural un saber sobre la humanidad y la sociedad, un saber etnográfico, antropológico y sociológico en pugna con las versiones tomadas de la oralidad secundaria o retórica; es decir, una escritura científica que procede ya no de acuerdo al código de la oralidad, sino de la escritura (DUCHET 1995). La retórica que sirvió de apoyo a la memoria oral resultó insuficiente al cobrar mayor importancia el sentido de la vista sobre el del oído y dar cuenta así de una mayor complejidad y extensión del mundo en la que el individuo era sólo un componente más entre otros. Así, la escritura surgió como el soporte del pensamiento científico.

Retomando la idea de la comunicación como probabilidad de la improbabilidad -que, por cierto, se aleja de las tesis del consenso y de la comprensión de las hermenéuticas tradicionales al estilo de Habermas o, en algunos aspectos, al de Gadamer-, la pregunta clave para reconocer la evolución de la verdad en la historia sería: ¿qué clase de recursos desarrolló ese tipo de comunicación basado en la escritura para reforzar, para hacer probable lo improbable de la "comunicación científica"? Si la retórica cumplió la función de hacer posible la imposibilidad de la comunicación cara a cara, ¿qué clase de "retórica" tuvo que desarrollar la modernidad para hacer posible lo imposible en las relaciones de la comunicación a distancia impuestas por la lógica del escrito y del impreso? ¿Qué clase de escritura tuvo que desarrollar para conseguir el aval de un público lector situado del otro lado del observador empírico que no era testigo presencial de las situaciones ni copartícipe de la memoria representada en el escrito? ¿De qué manera se generó la confianza necesaria para hacer creíble que la narración de los hechos, de los hallazgos y experimentaciones era digna de crédito y no producto de un engaño?

En relación con la cuestión acerca de cómo la "modernidad científica no retórica" se las arregló para resolver los problemas de la improbabilidad/ probabibilidad de toda comunicación dentro de los márgenes de mayor complejidad propios de la escritura, Luhmann, en su teoría sociológica, planteó -en discusión con Parsons - que el lugar de la retórica había sido ocupado por los medios de comunicación simbólicamente generalizados. Medios de esa clase son el dinero (para la economía), el derecho (para la política), la verdad (para la ciencia) y el amor (para la intimidad) (LUHMANN 1998, p. 9-73).

De hecho, creo que en los linderos de estas cuestiones y de este enfoque se inscriben las contribuciones de algunos sociólogos e historiadores de la ciencia que muestran que la generación de nuevos saberes no sustentados en la memoria introspectiva requirió el desarrollo de un nuevo virtuosismo o "civilidad" con el fin de generar la confianza necesaria para su aceptación. Entre esos autores se encuentran, además de Kuhn y Steven Shapin, otros como Alexander Koyré, Bruno Latour o Lorraine Daston.

Al considerar el ensayo de Shapin "La gran civilidad: Ia confianza, la verdad y el orden moral", se puede pensar en la comunidad de historiadores y en el proceso que condujo a la institucionalización de la historiografía entendida como "científica"; es decir, como un espacio equipado de un instrumental técnico, 
epistemológico y órganos de difusión (publicaciones periódicas y libros), espacio desde donde se pronunciará un tipo de enunciados sobre el pasado frente a una sociedad dispuesta a aceptarlos como verdaderos. Se trata de enunciados factuales correspondientes a estados de cosas reales, similares a los enunciados que comenzarán a generarse en Europa en el siglo XVII, del tipo: "El aceite de olivo se congela en un invierno ruso".

Si se sostiene que la verdad histórica no cambia, se debería suponer también que no hay lugar para la sociología y la historia. Se seguiría suponiendo también que las verdades son universales en la medida en que no dependen ni del espacio ni del tiempo de la observación. Pero si se asume lo contrario, entonces habría que mantener la postura de que no hay producción de verdad independiente de la sociedad en la que se produce. En este caso, la verdad pierde su carácter de sustancia inmutable y se convierte en un bien que evoluciona en el marco de las colectividades, de manera que su evolución ya no puede adjudicarse a un individuo que define la pertinencia de la selección de su investigación, sino al funcionamiento de una colectividad que establece sus selecciones y las estabiliza. En esa medida, el estudio de la historia es motivo de la sociología.

Dentro de esa perspectiva configurada desde hace un medio siglo en los trabajos de historia y sociología de la ciencia, una historia social de la verdad histórica anularía las visiones románticas y heroicas dominantes en las que los historiadores suelen aparecer como seres privilegiados que portan y hacen la verdad en la historia. A la luz de ese postulado habría que observar cómo el 3.58 conocimiento histórico ha sido el resultado de las evaluaciones y acciones de una comunidad determinada, delimitado por la incorporación de las demandas de conocimiento y del comportamiento institucionalizado de la comunidad. En ese sentido, las comunidades de historiadores tendrían que describirse a partir de sus "economías de verdad" (SHAPIN 1994, p. 5). Esas "formas" pueden ser observadas en sus locuciones sociológicas, filosóficas e historiográficas.

El desarrollo de la pragmática lingüística ha permitido iluminar un segundo aspecto relacionado con la constitución de la verdad en el seno de una comunidad. Un análisis pragmático de las locuciones dejaría ver, por ejemplo, cómo los juicios de verdad culminan no puramente en una visión del mundo, sino en una manera colectiva de actuar. A ese respecto, la verdad consistiría no meramente en la formulación de una idea aséptica, sino en la capacidad de generar acciones que convierten esa idea en "verdadera". Este paso - que coincide con el problema de hacer posible lo imposible en la comunicación- está propuesto en la investigación de Shapin en términos morales para la conformación de las comunidades científicas durante los siglos XVII y XVIII.

Dada la naturaleza colectiva del hacer o producir verdad en la historia, los individuos que participan en ese "juego" se necesitan mutuamente para cubrir sus requerimientos materiales, confirmar los estados de la cuestión, producir nuevos saberes e, incluso, para ser escépticos respecto de lo sabido. Por tanto, para que el saber pueda ser efectivamente accesible a un individuo tiene que darse también un vínculo moral entre el individuo y otros miembros de la comunidad. Si ese vínculo falla, la información que circula puede muy 
probablemente no culminar en comunicación y, por tanto, puede no haber "verdad". La palabra que designa ese "vínculo moral" es "confianza" (trust) que seguramente se podría traducir como "credibilidad" (Shapin). El problema de la verdad consistiría, entonces, en saber cómo un alter hace creíble para un ego que lo que está afirmando es cierto y no una mera opinión.

¿Cómo se consigue la "confianza" del otro? Eso solo es posible si se llenan las expectativas de acuerdos previamente contraídos. Ahora bien, si la verdad histórica pierde su carácter inmutable, debemos, entonces, preguntarnos cómo funciona ese de tipo de memoria que hace ver que los hechos del pasado tal como fueron pudieron haber sido de otra manera. Al desactivarse una epistemología histórica de corte "naturalista", se abre la disciplina de la historia a pensarse como integrante de un fenómeno mayor: el de la cultura y su relación con la forma en que las sociedades recuerdan u olvidan. ${ }^{12}$ Por ahora, esa parece ser la vía más plausible para superar el aparente relativismo y desconcierto entre quienes piensan en el fin de la historia tras haberse desplomado la epistemología clásica de la primera modernidad debido a la incorporación y diseminación social de los nuevos medios de comunicación electrónica del siglo XX. Desde "ese lugar" se ha considerado la posibilidad de reescribir la historia de la disciplina de la historia, o la de redescripción de la evolución de la "economía de verdad" de la comunidad de historiadores inscrita en el tiempo, en la que entran en juego principalmente cuatro vocablos: historia, ciencia, verdad y credibilidad. ${ }^{13}$

\section{Referencias bibliográficas}

BREDEKAMP, Horst. La nostalgie de I'antique: statues, machines et cabinets de curiosités. París: Diderot Editeur, 1996.

BELTING, Hans. La historia del arte después de la modernidad. Traducido por Issa Maria Benítez Dueñas. México: Universidad Iberoamericana, 2010 [2003].

BETANCOURT, Fernando. El retorno de la metáfora en la ciencia histórica contemporánea: interacción, discurso historiográfico y matriz disciplinaria. México: Universidad Nacional Autónoma de México, 2007.

BIZIERE, Jean Maurice; VAYSSIERE, Pierre. Histoire et historiens: Antiquité, Moyen Age, France moderne et contemporaine. Paris: Hachette, 1995.

CASACUBERTA, David; ESTANY, Anna. ¿Eureka? El trasfondo de un descubrimiento sobre el cáncer y la genética molecular. Barcelona: Tusquets, 2003.

COSTA LIMA, Luiz. Control of the Imaginary: reason and imagination in Modern Times. Translated by Ronald W. Sousa. Minneapolis: University of Minnesota, 1988.

\footnotetext{
12 A este respecto se es consciente de que se trata de un ámbito polémico que exige mayor clarificación: no todos los historiadores y filósofos de la ciencia compartirían este enunciado (CASACUBERTA; ESTANY 2003; ESTANY inédito).

${ }_{13}$ Precisamente sobre esta clase de problemas, Francois Hartog (2013) ha publicado uno de sus últimos libros.
} 
DANTO, Arthur C. Después del fin del arte: el arte contemporâneo y el linde de la historia. Barcelona: Paidós, 1999.

DE CERTEAU, Michel. L'écriture de I'histoire. París: Gallimard, 1975.

DIDI-HUBERMAN, Georges. Ante el tiempo: historia del arte y anacronismo de las imágenes. Buenos Aires: Adriana Hidalgo editora, 2008.

DOSSE, François. L'Histoire. Paris: Armand Colin, 2000.

DUCHET, Marcel. Anthropologie et histoire au siecle dês Lumieres. Postfacio de Claude Blanckaert. Paris: Albin Michel, 1995.

ESTANY, Anna. Cognitive approach on the relations science-technology. Manuscrito inédito (fotocopia).

FORASTIERI DA SILVA, Rogério. História da Historiografia: capítulos para uma história das histórias da historiografia. Sao Paulo: EDUSC, 2001.

GENETTE, G. et al. Théorie des genres. Paris: Du Seuil, 1986.

GOUBERT, Pierre; ROCHE, Daniel. Le français et I'ancien régime. 2: culture et societé. Paris: Armand Colin, 1991

HABERMAS, Jurgen. Conocimiento e interés. Traducido por Manuel Jiménez Redondo Madrid: Taurus, 1982 [1968].

. El discurso filosófico de la modernidad (Doce lecciones). Traducido por Manuel Jiménez Redondo. Madrid: Taurus, 1989.

HARTOG, François. Croire en I'histoire. Paris: Flammarion, 2013.

KANT et al. Was ist Aufklarung? Thesen und Definitionen (Erhard Bahr Ed.). Stuttgart: Reclam, 1980 [1783-1784].

KRIEGEL, Nadine. L'histoire a I'Age classique 3/ Les Académies de

I'histoire. Paris: Quadrige/Presses Universitaires de France, 1988.

LUHMANN, Niklas. La ciencia de la sociedad. Traducido por D. Pappe, B. Erker y L.F. Segura. México: UIA/Anthropos/Iteso, 1996

- Los medios generalizados y el problema de la contingencia. In: . Teoría de los sistemas sociales (artículos). México: UIA/ ITESO, 1998, p. 9-73.

. La forma escritura. Estudios Sociológicos, v. XX, n. 58, p. 3-21, 2002.

LYOTARD, Jean-François. La condición postmoderna. México: REI, 1990.

MAZIN, Oscar (ed.). Las representaciones del poder en las sociedades hispánicas. México: El Colegio de México, 2012.

MENDIOLA, Alfonso. Las tecnologías de la comunicación: de la racionalidad oral a la racionalidad impresa. Historia y Grafía n. 18, p. 11-38, 2002.

Retórica, comunicación y realidad: la construcción retórica de las batallas en las crónicas de la conquista. México: UIA, 2003. 
POMIAN, Krzysztof. Des saints reliques a l'art moderne: Venise-Chicago XIIIe-XXe siècle. Paris: Gallimard, 2003.

POOVEY, Mary. A history of the modern fact: problems in the sciences of wealth and society. Chicago: Chicago University Press, 1998.

QUINTANA, Angel. Después del cine: imagen y realidad en la era digital. Barcelona: Acantilado, 2011.

RUIZ-DOMENEC, José Enrique. Rostros de la historia: veintiún historiadores para el siglo XXI. Barcelona: Península, 2000.

SAHLINS, Marschall. La ilusión occidental de la naturaleza humana. Traducido por Liliana Andrade Llanas y Victoria Schussheim. México: Fondo de Cultura Econômica, 2011.

SHAPIN, Steven; SCHAFFER. Leviatán and the air-pump: Hobbes, Boyle, and the experimental life. Princeton: Princeton University Press, 1985.

A social history of truth: civility and science in seventeenth-century England. Chicago: Chicago University Press, 1994

. La revolución científica: una interpretación alternativa. Barcelona: Paidós, 2000.

SPENCE, Jonathan D. El palacio de la memoria de Matteo Ricci: un jesuita en la China del siglo XVI. Traducido por Mabel Lus González. Barcelona: Tusquets, 2002.

ZERMEÑO PADILLA, Guillermo. La historia común es bastante compleja. Historia y Grafía, n. 36, p. 75-104, 2011.

. De viaje tras el encuentro entre archivo e historiografía. Historia y Grafía, n. 38, p. 13-57, 2012. 